\title{
Experimental Study of Independent Learning Reform
}

\author{
Ruifeng Pan $^{1, a}$
}

${ }^{1}$ Jining Normal University, Wulanchabu, Inner Mongolia, China, 012000

aemail,

Keywords: Experimental Study, Independent Learning Reform

\begin{abstract}
With the advent of the learning society, the important mission of school education is to train students to become independent learners, so that they can continue to update themselves. Better ourselves and meet the challenge. Therefore, teachers Students' Ability to learn new curriculum development has become an inevitable requirement in the teaching process.
\end{abstract}

\section{Introduction}

Currently, a new round of basic education curriculum reform entered the popular deepen and crucial stage. This far-reaching program of reform with unprecedented strength and a new look, modern curriculum and teaching system has had a huge impact on every stage of basic education teachers have raised new issues and challenges. Implemented in the classroom teaching, the first is teaching philosophy and changes in teaching mode. The new curriculum emphasizes teaching mode, changing the way students learn and the way teachers and students interact, advocating for students to leave room for self-exploration and space, the pursuit of creative spirit and practical ability. It should be said, "a self-study guide" proposed reform experiment, precisely in response to the current trend of education reform, the interpretation of a number of key concepts of educational reform, and pay practice.

"A self-study guide" is the instructor and student independent study referred to, which is intended to achieve through instructor-student learning, the teacher speaks turning guidance, students learn by his master turned to independent learning. This is "a self-study guide" reform different from the traditional teaching of basic features. "Guiding a self-learning " classroom teaching should have the following essential characteristics: autonomy, focused, generative, activity, openness, inquiry, collaboration and sexual life.

In recent years, with the development of subjectivity education, social constructivism, humanistic theories, the importance of independent study attracted more and more attention from researchers. Although there are many domestic and international research on the independent learning model, however, the theoretical study of the independent learning model is still much to explore space. In this paper, autonomous learning theory, "recent developments" theory, humanistic theory and social constructivism theory advanced theory, construct the general rules and the basic model with a teaching guide of combining different grades and disciplines, the " a guide independent study "teaching mode applications, further verify the feasibility and operability.

\section{The Concepts of Self-Learning}

The so-called "self-learning" refers to students under the guidance of science teachers by motile creative learning activities to achieve the development of autonomy. Science instructor is a prerequisite and led, student is the subject of education, learning the subject; student active creative learning education center of activity is the basic ways and means of education; to achieve self-development is education and teaching activities purpose is the essential requirement of all educational activities. This refers to the narrow sense of "self-learning." Generalized "self-learning" refers to people through various means and ways to carry out the purpose Selective learning activities to achieve independent development.

To emphasize self-study student school curricular learning-based, while strengthening the students studying in the selectivity of the school, leaving students more selective learning 
opportunities and space; students should learn in order to book knowledge-based, and to strengthen learning to practice, continue to put on book knowledge learning and real life experience combined production; students to receive school education, at the same time to strengthen family education and social education; students will learn the knowledge-based, while strengthen training skills training and practice in learning and mastering the "what and why" at the same knowledge, to strengthen the "how-to" knowledge and skills education, in accordance with the requirements of quality education, through learning within the knowledge into quality, through skills training into quality, through exercise practice sublimation quality.

Independent study has established the dominant position of students from the root. We found that when people understand the dominant position of students, tend to believe that the dominant position of students by teachers 'leading role achieved without leading role of teachers, students' status does not exist, more difficult to achieve. Independent learning is clearly dominant position of students in active learning by the learners practices this decision itself. In the modern information society, more and more broad space for students, they can either learn under the guidance of teachers and parents to be completely on their own efforts to selectively learning. In either case, the learner is the subject, which is absolute, eternal, and the guiding role of teachers is relative.

Independent Learning emphasizes nurturing students a strong motivation and a strong interest in learning, thereby performing active learning, learning initiative voluntarily, rather than passively or reluctantly learning. Student motivation and interest in learning to cultivate and develop, is one of the important tasks of school education. This is because, student motivation and interest in learning, not spontaneous, naturally, but through the school, family and social aspects of education and guided formation. Only students with a strong, long-lasting motivation and interest in learning, independent study will be achieved. For a long time, under the yoke of examination-oriented education thought, schools and teachers tend to ignore students' motivation and interest in learning to develop education, to take "control entrapment" approach or simply relying on exams and academic pressures to "inspire" students' motivation. This practice most students not only ineffective but harmful, must be changed as soon as possible.

Independent study emphasized that students should learn creatively. The so-called creative learning means within the grasp of the knowledge learned in the process, namely the integration of knowledge and construction process on the basis of a deep understanding. Can really understand, it is the key to the learners to gain knowledge. By understanding and learning, in order to understand and learn, which is the basis and key to creative learning is an important concept of autonomous learning.

Teachers guide and help is extremely important for the construction of knowledge and self-development of students. Teaching teachers to be creative, we must correctly understand and apply the three kinds of teaching ideas. Judging from the current practice of teaching primary and secondary schools, the people mainly used to "talk - Science - practice" teaching ideas in self-learning teaching practice reform, vigorously strengthen the "school - talk - practice" and "learning through problem solving "teaching ideas, in a certain sense, the latter two teaching ideas is the core idea of independent learning work. To form a lively student-centered learning situation, we must start from the concept of the reform of education, strengthen the "learning problem solving," while the reform of teaching content, teaching materials and ideas to make the problem situations, free discussion and classroom-based operations. To adapt to this change, teachers must constantly improve their educational theory literacy, enrich their own practical experience.

\section{Self-Learning Educational Practice Will Bring Fundamental Changes in Educational Philosophy}

Independent Study relates to a fundamental change educational theory and practice of teaching in many aspects, especially in educational philosophy will bring fundamental change. In order to adapt learning, we need to establish the following concept.

Establish an Idea of Educational Subject Autonomy Development. Education is to train human activity, modern education and modern production is a modern way of life based on modern 
technology and modern culture as the background, to stick with the combination of productive labor, to foster the development of personal autonomy for educational purposes. Modern social development needs of modern education and training must have an innovative spirit and ability. Currently, our educational theory and educational practice there are drawbacks and one of which is ignored and even despised the subject of education in the process of training people in the development of autonomy. The performance of the implementation of the uniform pattern of education, only concerned about the mastery of knowledge, ignoring the spirit of innovation, foster innovation and personality development, resulting in students passively learning, hands-on practice with the poor, to participate in awareness and participation is not strong and so on. Independent Learning education reform experiment in autonomy development as the main starting point and basis for education reform, the current education irrational, ways of thinking and behavior fundamental transformation, trying to achieve the concept of educational theory and educational change.

Establish a Modern Teaching Concept of Taking Learning as the Core. Meet the needs of the era of knowledge economy and learning society, the traditional teaching concept needs fundamental change. Key changes in three aspects. First, we must build to the subject of education and the Independent Development of Innovative Education Centre theoretical system of modern education, the establishment of modern educational theory of "learning to learn" as the core content. The second is "learning theory" transform the existing "teaching theory", the establishment of "learning theory" as the center of modern teaching concepts. Autonomous learning requires learners to establish the status of the real subject of development and self-development, teaching theoretical knowledge economy era is more in line with learners knowledge, skills and personality development inherent laws, teachers of the so-called "teaching" and its true meaning from the past "teaching students knowledge and skills" to "teach students how to learn." The third is to study learning method centered pedagogy driven by the concept of fundamental change. Constructing the study of law centered pedagogy theory system, and continue to promote this method of teaching Practice.

Establish a Scientific Study Concept of Taking Understanding as the Core. Teachers enable students to become the subject of self-learning, learning is a must establish understanding, the concept of memory, the use of the process, students' mastery of knowledge is a preliminary understanding, strengthen memory, learn to use, to deepen understanding of the process. Essence and core of the learning process is to understand, rather than memory. Establishment of such learning concept learned to make more stable, more flexible, knowledge has become possible to make creative wings.

Establish a Dynamic, Structural View of Knowledge. Autonomous learning, teachers should establish the scientific concept of the structure of knowledge, it is necessary to pay attention to the teaching of book knowledge, but also to guide students to pay attention to the accumulation of experience and theorizing; students should not only focus on learning "what" and "why" knowledge, more attention should be paid to the "how" of learning knowledge. In quality education to efforts to solve learning problems structured knowledge.

Independent Study reform experiment should pay attention to the problem. Individual students' independent learning and cooperative learning groups are two basic forms of independent study. Independent study conducted independently can be an individual and group cooperation can also be carried out. It is also a cooperative learning content requirements. We do not have individual learning based collaborative learning is like castles in the air, without individual independent thinking and expand exchanges and discussions as a source of water. Cooperative learning cognitive function must have a clear positioning, cooperative learning to address the difficult subject cannot be solved by a panel discussion, inspire each other to achieve the complementary advantages and common resolving. Individuals through independent study can solve the problem need not be discussed in the group. Leaving individual students independent learning and deep thinking, mutual exchange and discussion between the impossible depth, no real interaction and inspiration for different views perspectives within the group simply cannot endorse or oppose the proposed real 
sense, cannot do an effective component draw correction, self-enrichment of view, this is invalid cooperative learning, it can not only promote each other, but in virtually deprived of independent thinking, independent study opportunities.

In the "guidance of a self-learning" in the classroom, the classroom became a school room, classroom into the school, students to become true masters of learning, students mainly study the way in the classroom is an individual and independent learning cooperative learning groups and interactive learning in large classes It can be said that learning activities, content and tasks rely mainly on the students themselves to complete. However, generally speaking, students through independent study generally only solve the problem of shallow areas and the problems of the prior development of the book, but the underlying problem.

Autonomous learning reading behavior (capacity) showed more receptive learning, this learning is characterized by knowledge based on the conclusions presented in the form of direct and its manifestations by the strength of student autonomy law can be divided into lectures, reading tutoring and self-learning method. In contrast, his main teaching method is learning and reading tutoring especially self-rule is self-learning. Thoughts of self-learning behavior (capacity) showed more inquiry-based learning, this learning is characterized by problems of knowledge in the form of indirect presented its manifestations by the strength of student autonomy law can be divided into an independent inquiry found that a method Study method.

\section{Conclusions}

In the independent study reform experiment, we should conscientiously sum up our reform existing experience and learn from a wide range of experience and the introduction of advanced educational reform at home and abroad to study the theory of education and teaching as an important basis for the experiment, and strive to achieve good test results.

\section{References}

[1] Ji Kangli. Western Boundary, Vol. 3 (2002) No 53, p.28-34

[2] Bai Chenghua. Education Series, Vol. 12 (2005) No 27, p.127-130

[3] Wang Tan. Educational Research, Vol. 30 (2004) No 19, p.152-156

[4] Yu Wensen. Chinese Society of Education, Vol. 29 (2007) No 27, p.158-161

[5] Zhang Gongxu, Sun Jing. China Education Daily, Vol. 8 (2003) No 27, p.57-60 